\title{
Strategic Choices and Organizational Challenges in Times of Crisis: Illustration of the Experience of Two Moroccan SMEs
}

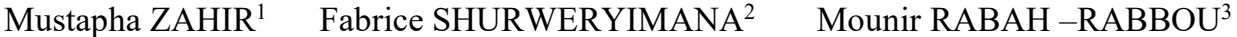 \\ 1.School of Technology Essaouira, Cadi Ayyad University of Marrakesh, SAEDD laboratory, Morocco \\ 2.Haute École de Management- HEM- Casablanca, Morocco \\ 3.GECIAS Laboratory, Hassan II University, Casablanca, Morocco
}

\begin{abstract}
The aim of this work is to show that organizational change is a response to certain problems generated by a market specialization strategy. Our study is based on two cases of SMEs that first engaged in a business relationship with a single client for more than five years. This led to a high degree of skills specialization and a certain organizational rigidity which was subsequently detrimental to the continuity of the company's activity, particularly when the relationship with the only single client was unexpectedly concluded, for the client had become increasingly demanding in terms of cost and time. Analysis of the data shows that both SMEs have made a series of organizational changes (restructuring of the company, recruitment of new skills, training activities, use of partnerships with other organizations, etc.) to overcome this perilous situation. As a consequence, these companies were able to reorient their business policy in order to reduce their dependence and then ensure their business sustainability and growth.
\end{abstract}

Keywords: Organizational change, dependency situation, customer-supplier relationship, strategic choices.

DOI: $10.7176 / \mathrm{EJBM} / 12-27-04$

Publication date:September $30^{\text {th }} 2020$

\section{Introduction}

Since some decades, the evolution of industrial and commercial challenges (increasing demand for flexibility, quality and low costs; the accelerate rate of innovations and development of new products; the drastic reduction in production lead times and the consumer volatility; etc.) has made increasingly difficult to manage several activities in an integrated manner within the same company, which impacts negatively the markets competitive advantage. This encourages most firms to refocus on a few and easily manageable fields and to delegate several of their activities to seasoned suppliers, who are now considered business partners and not alike simple merchants who can be easily substituted. This movement leads to a reconsideration of customer-supplier relationships and implies the participation of each party in building competitive advantage. The success of the customer and the supplier are then closely intertwined and involve a harmonized management of their related activities. For some suppliers, particularly small entities, the requirements of this new situation lead them to focus in a limited number of activities and customers, in order to improve their competitive power, while hoping for the sustainability of their relationships with customers. However, if this market/customer specialization is in some cases a source of success for SMEs, it can also be a source of many difficulties, especially for single-customer SMEs. This research shows, in fact, how a customer specialization strategy can be detrimental to their survival, especially when the conditions of environmental competitiveness change to their disadvantage. Based on the experience of two Moroccan SMEs initially engaged in a business relationship with a single customer for a period of at least five years, our research highlights how this situation of dependence leads to a high specialization of their skills and a certain rigidity in their organization, which makes it difficult for them to continue their activities, especially when the relationship with the single customer fades. It shows, however, that a strategic repositioning supported by some organizational changes is a response to some of the problems caused by this market specialization. The data from the two SMEs show that a series of organizational changes have enabled them to reorient their business policy to reduce dependency and ensure the sustainability of their activities. We present in the following lines the theoretical foundations of this research, the methodology used, as well as the results of the analysis of the collected data.

\section{Theoretical framework of the research}

\subsection{Customer-supplier relations: between a transactional approach and a partnership approach}

Inter-firm relations, in general, and those between customer-suppliers, in particular, can be analyzed through several theoretical backgrounds whose considerations and implications differ however. They can be analyzed as a framework of rationalizing simple transactions, based on their frequency, their costs and the coordination problems they generate (transaction cost theory). They can also be studied as a framework for long-term bilateral cooperation which goes beyond the logic of rationalizing transaction costs alone (resource dependency theory).

In the first sense of analysis, the theory of transactions costs initiated by Coase (1937) and subsequently developed by Williamson (1975) is concerned with the study of institutional arrangements used to organize economic activity. It proposes alternative forms of governance to manage transactions effectively and efficiently. 
In particular, it takes into account the uncertainty of the environment, the frequency of the transactions and the degree of the assets specificity needed to carry out these transactions, in order to explain the choice between the market, the hybrid form or the hierarchy, considered by Williamson (1985) as the three alternative forms of organization of economic activities. Uncertainty would result, on one side, from the informational asymmetry between the parties to the relationship and, on the other side, from the inability to predict all the scenarios that may arise because of the limited rationality of the actors and also because of the complexity of the environment, which has become increasingly turbulent (Williamson, 1975). Thus, depending on the perception of this uncertainty (low or high), some authors (Coeurderoy and Quelin, 1998) show that firms can either internalize its effects (when it is low) or pass them to their suppliers (when it is high).

About the specificity of assets, every company needs a number of tangible and intangible assets to streamline its value chain, and therefore relies on other companies to acquire them. However, given that, in general, any asset in a transaction is characterized by a level of specificity ${ }^{1}$ that necessarily influences the nature of the relationship between the parties, it turns out that the more specific the asset required for a transaction, the more firms will choose to use the market rather than the hierarchy. However, it is recognized that some firms may also choose to enter into long-term relationships, like partnership, given their competitive expectations. Finally, the frequency of transactions is considered to choose a better mode of governance of transactions according to the comparative efficiency of each organizational alternative. In this sense, if the transaction is one-off, it is in the company's interest to resort to the market. If, on the contrary, it is recurrent, the choice of a relational type of governance mode will be favored (Rinehart et al., 2004).

However, despite the interest and importance of this approach in the analysis of inter-organizational relationships, it allows only a partial analysis and understanding of the current dynamics of these relationships. It considers a customer-supplier relationship to be an efficient way of organizing as long as it minimizes transaction costs. It fails, however, to take into account the impact of the duration (past and expected future of the relationships) and the social embeddedness of certain relationships (resulting from the multiplicity of personal networks) which would limit the emergence of deviant behavior and opportunism (Dwyer et al, 1987; Quélin, 2003), through effects of reputation, intimacy and emotional greatness (Granovetter, 1973). Letourner (1994) also demonstrates that in partnerships, exchanges are not independent episodes but rather take place in a dynamic stream of the relationship, building on previous episodes (learning) and reciprocal adaptation (interactions).

Furthermore, in view of the rising complexity, the speed of change and the rapid obsolescence of products, it is becoming increasingly consistent that the creation and coordination of sustainable customer-supplier relationships no longer takes only into account the level of transaction costs. Some works point out that a firm may resort to partnership not only for reasons of economic efficiency, but also and above all for organizational and social considerations and for access to external skills; this further underscores the importance of interdependence in the formation of such relationships (Altersohn, 1992; Saget 1988; Dwyer et al, 1987; Quélin, 2003). Hence the usefulness of using resource dependency theory to capture these types of relationships.

This theory, derived from resource-based approaches, generally considers that organizations do not have sufficient resources and skills to meet the needs of clients, which is why the overriding logic of cooperation would be to borrow resources and skills from external partners (Soussi, 2002; Donada and Kesseler, 1997; Hamel and Prahalad, 1990; Zahir, 2015). Thus, as noted by Donada and Kesseler (1997), in accordance with the studies of Lamming (1993), Garel (1994), Donada (1997) and Laigle (1996), suppliers with a portfolio of scarce and rentgenerating resources sought by customers would earn much higher returns than those without. Hence the importance of strategic resources (specific assets, learning capabilities, etc.) as a discriminating factor for supplier firms. Thus, many companies would increasingly join together in common projects leading to mutual and sustainable interdependent relationships, as soon as they find an interest in working together (Midler et al., 1997; Rejeb et Ghorbel, 2004; Dwyer et al, 1987; Quélin, 2003; Zahir, 2015). Nowadays, to be successful, companies must acquire and create new knowledge, disseminate it inside and quickly incorporate it into new technology and products, as to continuously develop innovations (Martínez-Costa et al., 2019). Innovation opportunities are strategic components through the combination of know-how between the contractor and the subcontractors which are considered as suppliers with innovation and absorptive capacities (Nwokocha et al., 2019).

In this type of relationship, it is common for the parties to invest in assets specific to the relationship in order to strengthen their ties and allow the relationship to develop over time. Selnes and Sallis (2003) and Chang and Gotcher (2007) especially emphasize that relationship specific assets enhance learning within the relationship and add value for the partners through the development of common relationship capital (Zahir, 2015). This would encourage some providers, especially those that are small and have limited resources, to focus on the activities of a limited number of specific clients, enabling them to offer products and services that are better suited to their needs, despite the risks traditionally associated with specific investments (especially the risk of opportunism). It

\footnotetext{
${ }^{1}$ Assets are considered to be specific when a durable investment must be undertaken to support a particular transaction and that investment is not redeployable to other transactions, given their specialization, their location or the absence of a second-hand market (Brousseau, 1993).
} 
should be noted, however, that as the number of clients decreases, relationships would tend to become more exclusive, and the threat to the supplier of developing specific skills and assets that are difficult to redeploy to other relationships would become more serious and would increase the supplier's dependence on its clients (Baudry, 1995). Altersohn (1992) even points out that if power relations are in favor of the customer, he may well impose certain excessive constraints on his supplier, thereby accentuating the perverse effects of dependence. In these circumstances, the risk is much greater for suppliers who choose a strategy of exclusive commercial relations with a single customer, because of the highly specific nature of the assets they are led to develop in the context of this relationship. Then, we see trust as a very important factor in collaborations and at low level of trust, it might cause value co-destruction (Järvi et al., 2018). Mainly in nowadays context where firms share specific assets and capabilities which are key ingredients for innovation (Zahir, 2015; Palumbo \& Manna, 2018; Collinson \& Liu, 2017).

In the case of disagreement or opportunistic behavior on the part of their clients, suppliers may find themselves in a situation that is difficult to control, ranging from a complete and sudden cessation of activities to a complete overhaul of their offer and business strategies. The use of a series of organizational changes in such a situation sometimes proves to be indispensable for survival.

\subsection{The maintenance of organizational changes: a leveraging factor for developing and stabilizing customer- supplier relations}

As the survival and sustainability of a company is closely linked to its capacity to adapt to environmental change and its ability to satisfy all its various resource providers (Carton and Hofer, 2006; De La Villarmois, 2001; Shurweryimana, 2015), the establishment by a supplier of lasting partnership relationships with its various stakeholders is one of the sources of its sustainability. Evolutionary theory, devoted to the dynamics of the evolution and transformation of firms in response to environmental pressures, through a process of selection, retention and variation within a population (Nelson and Winter, 1982; Hannan and Freeman, 1977), emphasizes that only those entities that are able to adapt and adopt some active behaviors within the population resist its selective pressure (Arena and Lazaric, 2003; Stoelhorst and Bridoux, 2006). However, for a supplier in an exclusive commercial relationship with a single customer, it is more difficult to develop strong capacities to adapt to persistent environmental variations (Shurweryimana, 2015). This is because of the path dependency and organizational inertia (Hannan and Freeman, 1984; Nelson and Winter, 1982) that result from the high specialization of its assets and relational behaviors (focused on a single customer). Indeed, companies only learn on the basis of what they already know (Cohen and Levinthal, 1990; Zahra and George, 2002), which is why the evolution of a supplier engaged in a single relationship with a single customer cannot be random but rather grounded in very specific trajectories resulting from the skills it has previously accumulated (Ayerbe and Fonrouge, 2004; Schlink, 2006; Soulas, 2006; Shurweryimana, 2015). In some cases and over time, this situation can lead to a certain organizational myopia on the part of the supplier with respect to the evolution of business practices within its environment, which can increase the risk of being overtaken by competitors (Dosi and Nelson, 1994; cited by Sapprasert, 2008b; Shurweryimana, 2015) and then succumbing to environmental selection (Cyert and March, 1963; Romanelli and Tushman, 1994).

In order to overcome such difficulties, the supplier should reduce the specialization of its assets generally dedicated to a single customer and make its organization receptive to the behavior of other entities in its environment, in order to lessen the possible risks of organizational inertia and/or environmental selection (Shurweryimana, 2015). The development of dynamic routines (Nelson and Winter, 1982), known as firms' abilities to generate newness (Schlink, 2006; Quach, 2006), is more important in this case; these routines enable suppliers to often question their operations and routines in order to generate new skills (Doz, 1994). In this perspective, the contributions of the theory of "change readiness" can be useful. Successful implementation of a change often implies the introduction of something new into the organization or its routines. In that line, the change readiness theory maintains that resistance or blockages can slow down or precipitate the failure of the change. This is due in particular to the inertia of certain contextual components of the organization (Kamaruddeen et al., 2009), such as its history, culture, structures and management systems, without forgetting the human dimension, which is crucial in terms of resistance to change (Perret, 1996). This approach thus proposes that instead of trying to control the change process by steering it, the essential thing is rather to create the organizational conditions necessary for its success (Soparnot, 2009). More concretely, it advocates rooting change in organizational processes (Armenakis et al., 1993), making it continuous and permanent so that it becomes routine (Brown and Eisenhardt, 1997) and appears to employees as a necessary solution to cope with the constraints of environmental adaptation and the sustainability of the company (Perret, 1996). The present research is part of this path and shows how two Moroccan SMEs, which were initially engaged in exclusive customer-supplier relations with a single customer, were able to reorient their strategies and evolutionary trajectories in order to get rid of their relational dependency and, above all, to face their problems of organizational inertia inherited from their previous relations, while improving their performance. 


\section{Research methodology}

Our research is fundamentally exploratory in nature and focuses on analyzing and understanding how, in a crisis situation resulting from a failing customer-supplier relationship, SME suppliers can successfully achieve their strategic repositioning through organizational change. In order to meet our research aims, a qualitative approach based on two case studies (automotive and textile industries) was selected. The choice of the qualitative approach is justified both by our interest in deepening the analysis of the phenomenon but also and above all by the complexity and exploratory nature of the research problem. Data was collected through three sources ${ }^{1}$, namely the semi-directive interviews, internal documents and non-participant observation. Table 1. Characterization of the SMEs studied

\begin{tabular}{|l|l|l|}
\hline & Company " Auto " & Company " Textile " \\
\hline Activity & Manufacture of plastic parts & Manufacture of high-end men's trousers \\
\hline Creation date & 2006 & 1999 \\
\hline Staff & Less than 100 employees & 200 permanent employees \\
\hline Turnover (DH) & Approximately 70 million & Approximately 35 million \\
\hline Market clients & Automobile manufacturer & $\begin{array}{l}\text { Well-known Multinationals companies in the } \\
\text { fashion industry }\end{array}$ \\
\hline Location & Casablanca & Casablanca \\
\hline
\end{tabular}

The data analysis method we have chosen was inspired by the approaches proposed by Miles and Huberman (2003), Wacheux (2003) and Thiétart (1999). It consists of classifying the empirical material collected based on themes selected through the interview guide. After categorizing the collected data, we used the technique of thematic data analysis to construct our results.

Table 2. List of interviewees

\begin{tabular}{|l|l|l|}
\hline & Company " Auto " & Company " Textile " \\
\hline Activity & Manufacture of plastic parts & Manufacture of high-end men's trousers \\
\hline Creation date & 2006 & 1999 \\
\hline Staff & Less than 100 employees & 200 permanent employees \\
\hline Turnover (DH) & Approximately 70 million & Approximately 35 million \\
\hline Market clients & Automobile manufacturer & $\begin{array}{l}\text { Well-known Multinationals companies in the } \\
\text { fashion industry }\end{array}$ \\
\hline Location & Casablanca & Casablanca \\
\hline
\end{tabular}

\section{Main results of the research}

\subsection{Strategic choices adopted and effects of the dependent situation}

At the date of creation, the relationships between the SMEs studied and their main customers were characterized by a high degree of dependence, in the sense that the share of turnover generated by these relationships exceeded $95 \%$ in both cases. This led these SMEs into a crisis situation after a few years, especially when the key clients decided to break off their relationship in favor of other more competitive suppliers.

4.1.1 Nature of the studied relationships: towards total dependence

As noted earlier, the relationships analyzed in this research were initially characterized by a high level of dependency. This situation of total dependency led the SMEs to face a number of problems, especially through the crises of 2005 and 2008, which led to a drop in orders. Given the almost exclusive commercial relations of the two SMEs with a single customer, their investments have always been dedicated and committed to serve only the expectations and production of goods of the one main customer. After a few years of collaboration, the breakdown of the relationship with their respective main customers, especially at the height of the economic crisis, led to serious problems, particularly financial, as they were unable to make profit on their project. Moreover, these clients demanded from their suppliers to undertake new investments in order to accompany them in their development. This seemed impossible because they were SMEs which often suffer from a lack of resources and means. Additionally, in that context, the evolution of their level of activity also shows the effect of this risk of strong dependence, as these SMEs were subject to fluctuations in their customers' orders, which often disrupted their internal planning and organization.

Similarly, it appears that the relationship between the customers and these two SMEs was characterized by customer dominance, mainly due to their weight in the overall turnover of these two entities. Interviews with officials tend to show that the clients of these SMEs adopted a strategy of coercive influence, in that they imposed certain constraints and required certain rules and procedures to be established. It thus appears that the customers had power over these suppliers and consequently obliged them to align themselves with their requirements and

\footnotetext{
${ }^{1}$ It should be pointed out that the main technique used for data collection is semi-directive interviews with the various managers of the company.
} 
benchmarks, through mainly formal controls on results and work processes. In the same line of ideas, it is perceived that there was a domination effect when managing disputes between the parties. The analysis of the evolution of their relations shows that the studied SMEs experienced tensions and sometimes difficult moments when clients always tried to impose their own analysis and interpretation on the points that were causing problems.

Another consequence of this total dependence on a single customer is the lack of monitoring activities and practices, as in both cases, the SMEs studied focused more on the satisfaction of the main customer, especially in the early years of existence (before the relationship broke down), and did not integrate into their culture the need to set up monitoring practices, possibly to prospect for new markets. Similarly, for each of the two SMEs, customer specialization led to a strong specialization of assets and skills, which were always designed to meet only the needs of the main customer, and then greatly weakened any possibility of developing their innovative capacities. For example, in the case of the "Auto" company, all assets were exclusive to the automotive sector, which caused many redeployment problems when the relationship was terminated. A series of adjustments and adaptations were necessary to develop new response capacities, according to new needs from industries other than the automotive sector. As result of these weaknesses, both in their skills and in their capacity for innovation, these SMEs lost their attractiveness in regard to their competitors. Expressly, the breakdown of their relationships and their customers' recourse to other suppliers was motivated by their inertia and rigidity, which no longer met the needs of the market and the conditions of competitiveness within the two sectors studied.

Thus, in order to face these difficulties caused by dependence on a single market and customer, the managers of the two SMEs decided to reconsider their strategies and commercial policies. A diversification of customers and products was adopted and a number of organizational changes were initiated to enable their entities to revive their competitive situations. As an example, one of the SMEs recognized that some organizational changes were essential to address some of these organizational difficulties, especially as this was a first experience in a sector said more demanding in terms of rigor and deadlines. Previously, these organizational problems were particularly affecting its service rate, which then disrupted the client's production line. To overcome this obstacle, changes in management, and therefore in management style, were carried out and the new appointed team was able to improve internal responsiveness and logistics performance indicators.

4.1.2 Strategic orientation Change: from specialization to client diversification

The change in strategic market orientation within the two SMEs covered in this research was a major turning point in their development trajectory. Since their creation, the two companies had devoted all their production to a single customer. Moreover, the relationship established between the "Auto" company and its client began at the creation of the company, which had been specially created to accompany the client in the development of its projects in Morocco (the investment was designed and made solely for this client). Similarly, a relational exclusivity was required by the client of the SME "Textile", before any business relationship between the parties was developed. However, during the crises of 2005 and 2008, the relations developed by the two SMEs with their clients had to be interrupted, despite their privileged nature. This provoked a deep strategic and organizational questioning in both SMEs. Their customer specialization strategies had led to organizational myopia and inertia (orientation of the company's capacities and investments to the satisfaction of the sole customer) which were no longer in line with the new strategy of the two SMEs to deal with the breakdown in their collaboration with their sole and main customers. They no longer wanted to serve a single customer ${ }^{1}$ and therefore had to set up an organization adapted to a diversified customer base.

Similarly, following the global crisis and the severe competition in the two sectors studied, the two SMEs could only be part of a cost leadership strategy, as their customers were, in fact, attracted by a company's ability to continuously reduce its costs. For example, in the automotive sector, the search for productivity, combined with the need for flexibility and cost reduction, had led customers to prefer foreign suppliers, with whom they had developed experiences in several markets, rather than retaining local suppliers, who were in most cases considered unable to support them in their projects. As a result, the SMEs studied were obliged to find an organizational arrangement that gave them highly competitive productive capacities in order to attract and retain such clients. In addition, these SMEs also had to demonstrate a capacity for innovation in order to be able to respond properly to the required standards in terms of quality levels. A logic of continuous improvement in production processes and in organization was therefore a natural requirement for them.

It should also be stressed that the strategic importance the studied companies gave to their human resources, as a factor of competitiveness and sustainability, has led these entities to include HR practices in their strategic agenda, focusing primarily on employee motivation, loyalty and involvement.

Likewise, in order to be able to respond adequately to customer expectations, the two SMEs have become aware of the importance of the performance of industrial equipment in both sectors. They have therefore made considerable investments to modernize their production apparatus, through the acquisition of new machinery and

\footnotetext{
${ }^{1}$ The "Textile" company focused on finding new customers in other countries and the "Auto" company opted to adapt its offer to the new expectations of other local customers. For example, by 2013, the "Auto" company was already developing new technical products for other industries (industrial packaging, household appliances, sanitaryware, etc.)
} 
technologies, new equipment, etc. In the case of the "Auto" SME, the manager even considered appropriate to build a new and entire production unit dedicated specifically to the automotive sector. In general, these various investments and acquisitions often required organizational adjustments, particularly in terms of training or recruitment of new skills. However, it should be noted that although these new assets had advantages in terms of cost and quality control, they also increased dependence on customers and the business.

\subsection{Organizational change levers hosted}

Today, it is clear that organizational change, whether in an SME or in a large company, can only take place through the availability and mobilization of significant resources. All of the managers interviewed for this research underline the fundamental importance of financial resources in order to be able to remedy the many difficulties that had hindered the evolution and dynamics of the relationships studied. For the "Auto" company, for example, given its affiliation to a Group of companies, the mother company provided financial support to enable it to face its difficulties and to carry out the adaptations and organizational changes necessary to support its new strategic direction. It was the same for the textile company, where its manager had to draw on his personal and family resources to support the organizational revitalization project of his entity.

In addition to financial and human resources, the management teams have also been important levers in driving the changes in the two SMEs. For example, the passion of the head of "Textile" SME for his job and his network were essential catalysts for the innovations and changes made in his organization. They have enabled him to develop a willingness to continually surpass himself and to always strive for the best, as the demands of the business have encouraged him to constantly question his organization and managerial practices in order to align himself with international competitiveness standards.

Furthermore, the analysis of the data highlights the crucial importance of management style in the success of business relations with customers, through its role in involving employees and in driving the changes and adaptations necessary to meet customer expectations. Above all, it has been crucial in ensuring a social climate that motivates and retains employees and establishes friendly social relations, which has supported and made possible the success of the made changes. The case of "Auto" SME is a good illustration, which has had three types of leaders since its creation to make its change project a reality. Initially, the first team adopted a rigid management style, inherited from its experience with car manufacturers, who often display principles based on rigidity and bureaucracy, given the size of their organizational structures. These problems of rigidity also persisted after the arrival of the second director, who also came with the automotive sector mindset, due to his experience in this business. The management team believes that this director focused on the project and neglected the social aspect, particularly working conditions and interpersonal relations, which were crucial to the success of the change. In the end, it was with the last director, who was the bearer of a change project affecting the organization as a whole, that the company managed to put in place a managerial and social framework that would enable it to carry out its mission successfully. The testimony of the HR manager is in line with this: "... today, "thanks GOD", we have a CEO who takes the social side of the staff into consideration, he sympathizes with people. You can feel that senior management is there, it is involved, he wants to make changes for the good of the company". In this perspective, the main challenge for the management team was to improve internal communication and to mark a break with the management style that had dominated the company's operations since its creation. This change in management style has been accompanied by other changes, especially organizational changes, with the recruitment of skills capable of establishing a management style that meets the requirements and culture of the automotive sector, in particular the importance given to risk and proximity management, etc.

Both SMEs also favored the use of local resources. To overcome their internal shortcomings, the two enterprises entered into organizational support partnerships with external players. In particular, they joined the INMA program, set up by the Ministry of Trade and Industry to help Moroccan companies improve their internal operations. Similarly, they also asked their clients to provide them assistance in terms of improving and integrating new knowledge. The exchange of personnel between the parties seems to have been favored within the framework of the studied relations, especially to improve the sharing of experiences and to promote the appropriation of tacit knowledge.

\subsection{Organizational changes led by the two SMES}

\subsubsection{Organizational Restructuring}

In order to get out of the problems that have hindered the evolution of their previous relationships with their unique clients, the studied SMEs have undertaken a series of actions and changes. Analysis of the collected data from the two SMEs reveals their commitment to a number of new quality management practices to adequately meet customer expectations. Considering that quality is more in demand on the market and aware of its importance in the supplier selection process, the managers of both companies have proceeded to the certification of their entities (ISO 9001 version 2000 for the textile SME and ISO TS 16949 for the automotive SME). The main objective of this commitment was to be in line with the requirements of their environment. To this end, a process based 
operation was adopted to detect, as closely as possible, any malfunction likely to affect the dynamism and organization of their companies. Practices aimed at continuous improvement were therefore encouraged by both companies. For example, they have begun to encourage all their employees to systematically question themselves to improve their practices, while motivating them to propose new ideas and improvements deemed necessary for the good conduct of the company. In the same vein, a permanent formalization of good experiences has been introduced, in order to support learning and knowledge sharing efforts. This effort of codification has notably been encouraged in order to avoid the recurrence of mistakes made in the past.

Similarly, the institutionalization of the coordination of relations with the main clients has been established within the two SMEs studied. Weekly meetings with each client were set up to allow exchanges on the progress of orders, problems encountered each week, actions taken or to be taken, etc. The meetings were held at the end of each week. Regular visits to customers were also planned to increase the transparency of each company towards them and, above all, to enable them to make suggestions that could be used to improve their processes. In the same vein, business development practices have been strengthened by appointing a manager to prospect new markets, in order to avoid reliving the negative experiences of the past (breaking off relations with the sole and main client). The implementation of a new information system was also necessary in the sense that it constitutes one of the indispensable tools for mastering management and coordination, both internally and with the external environment

The organization of production was also reviewed within the SMEs studied. As they are commonly engaged on items, generally requiring increasingly shorter delivery times, the two entities undertook to reason their production in terms of the number of items manufactured per hour, in order to be able to improve their production rates. To this end, they each set up a methods department, the aim of which was to develop new methods to better organize production processes in order to produce the quantities ordered on time and at lower cost, while maintaining a better level of quality.

In addition, in order to allow the organization to function properly and to make decision- making more fluid, a decentralization process of power and empowerment of intermediaries has been initiated in the two SMEs. This internal operating logic has made it possible to adopt a working mode in semi-autonomous and above all multifunctional work teams, making it possible to improve learning and the sharing of experience and knowledge. In the same vein, internal continuous improvement meetings have been set up. For example, in the "Auto" company, many meetings are held at several levels: between the team leader and the operators; between the production manager and the team leaders; between the plant manager and the heads of functions; between the plant manager and the general manager, etc.

Finally, a reinforcement of skills, through the recruitment of new managers, accompanied the changes made by the two SMEs, in order to have qualified human resources with the prerequisites to succeed in the requirements of that specific context.

4.3.2 Culture change and institutionalization of certain practices

Aware of the speed of change in their fields (textile and automotive), and by a desire to avoid risks, the two studies companies have initiated a continuous prospection of sectoral and competitive developments, in order to remain competitive on the market. This has been materialized by the initiation of monitoring practices and by the participation of these SMEs in various trade shows, both locally and abroad, while maintaining permanent contact with public and associative actors in the field. This has enabled them to constantly collect the information useful for their improvement in order to keep themselves up to date on a regular basis. The nomination of a sales manager within the two entities is also part of this logic of monitoring and understanding market needs.

The two companies have also set up dashboards to manage costs and processes. The objective at this stage was to partially overcome the uncertainty inherent on order processing and delivery. A follow-up of performance indicators, both technical and logistical, was necessary to guarantee the proper fulfilment of orders. Likewise, to improve costs and lead times, the companies set up, on all their production lines, stations for the systematic detection of assembly defects, in order to reduce errors and quality defects. Finally, to further reduce delivery delays, it was decided to introduce an inter-organizational information system with customers, to enable effective monitoring of deliveries.

In terms of support, the two SMEs have put in place procedures for feedback. For example, during the integration of a new operator, the quality department carries out a presentation session of possible defects, through photos, in order to reduce the risk of their recurrence. Socialization practices are also adopted, with each operator being asked to observe his predecessor in his daily action, especially during the first days of integration. The objective of this first phase of the integration process is to show him/her the work approach and the various possible defects. During the second phase, the operator begins the execution of tasks while being monitored and evaluated on his efficiency and performance.

Systematic use of training has also been ratified in order to update, reinforce or constantly enhance employees' skills. It was decided to set a budget and a special training program at the beginning of each year, in agreement with all employees, according to their needs and preferences, while taking into account customer expectations. Training is conducted, depending on the case, either internally or externally, under the supervision of company 
managers or external experts, mainly those from customers or the INMA.

In addition, in order to respond effectively to occasional skills shortages, the two companies decided to implement employee skills and agility maps, so that their main abilities and maneuver possibilities could be assessed. These maps, which are regularly updated, enable these entities to manage unforeseen events, absences or periods of high production. Specific training to increase employee skill's flexibility has been introduced for this purpose. Likewise, before each operator is stated autonomous, it was decided to exercise him/her through all the positions in order to learn the skills and knowledge necessary for their execution.

\subsection{The changes impacts}

The organizational changes made by the two SMEs have helped to overcome some of the difficulties encountered in the evolution of their former single-customer relationships. Productivity and service levels have improved significantly as a result of the efforts made by all stakeholders. For example, in the case of the "Auto" company, managers believe that the organizational changes made, with the arrival of the new management team, have resolved the supply problems that previously caused delivery delays. Indeed, the analyses show that the SME was able to capitalize on its experiences to establish a new policy that allowed it to develop new relationships with new customers from other industries. The rigor and the level of requirements linked to the automotive sector undoubtedly contributed to the development of the company's adaptability, as the SME managed to find, in a short period of time, new markets to reduce the weight of the activity exchanged with the car manufacturer.

Also, the organizational changes undertaken by the two SMEs have resulted in an improvement in the social climate and internal relations, with a reduction in tensions and an increase in friendliness and internal cohesion. This atmosphere, in synergy with the employee benefits and profit-sharing practices put in place, has fostered the emergence and increased dedication of employees, a decrease in absenteeism and an increase in their involvement. As a result, the stability of the organization has been strengthened. It is also noted that with the organizational changes carried out, the dominant culture within the companies studied has considerably evolved towards the promotion of values built on mutual aid, cooperation, team spirit, sharing, recognition and performance, etc. As such, the structures put in place seem to stimulate learning by encouraging interpersonal exchanges, especially with company executives.

In terms of operational performance, the two SMEs highlighted an improvement in their operational skills and capabilities, following their modernization efforts which particularly led them to reduce their execution problems, to make daily operations more fluid, to further minimize time losses and quality defects, to improve the service rate of their customers, and to significantly increase their productivity. This has resulted in an improved sales performance, as both SMEs have been able to develop further relationships with new customers. This has reduced their dependence on a single market, which is considered dangerous especially in times of crisis.

\section{Conclusion}

The objective of this research was to show how organizational changes can be actuated to address the problems of dependency and organizational inertia that often arise in single- customer supplier relationships. It was first highlighted that the strategic choices made by SMEs engaged in single customer-supplier relationships can have a certain influence, sometimes negative, on the way they operate and organize themselves. As shown in the following figure, we have, in fact, observed that in certain situations, particularly when the assets needed to make exchanges a reality are too specific, the SMEs studied have forgotten to keep an eye open on the evolution of practices in their environment, focusing only on the skills needed in their relationship. This strong focus on the sole relationship with their clients has led to a certain rigidity and organizational inertia in their ways of doing things and in their skills, which has been detrimental to them subsequently. The SMEs lost their markets and had to resort to several organizational changes in order to get by, after having reoriented their commercial strategy (customer diversification). This is because of not having been able earlier to follow the market trend in order to offer competitive skills.

Although these results cannot be generalized in view of the limited number of the study cases treated, they do have the merit of highlighting the perverse effects of customer-supplier relations marked by a strong dependence of the supplier on a single customer. They show that partnership relationships are not always longlasting but are imbued with a certain rationality, which can lead one of the players to turn to other partners with varying degrees of performance. 


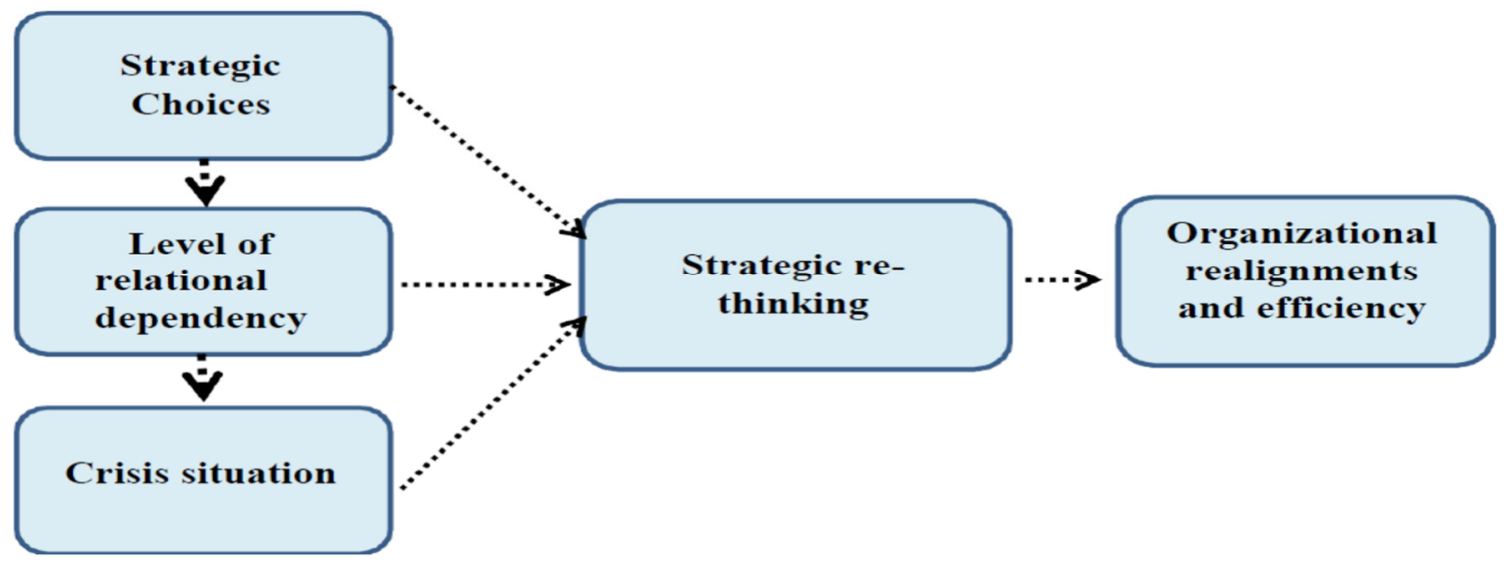

Figure 1. Conceptual model

For suppliers involved in single customer-supplier relationships, this implies limiting their strong focus to the customer's requirements and needs, even when the relationship seems advantageous. A good strategy would be to develop other skills and extra-relational capacities that would enable them to bounce back in case of a break-up. For future avenue, as highlighted by Liu et al., (2017), it is relevant to consider the value of the relationship between the contractor and the subcontractor in comparison to trust and commitment approach.

\section{References}

Alimadadi, S., Bengtson, A., Salmi, A. (2019). Disruption, dissolution and reconstruction: A dialectical view on inter-organizational relationship development. Scandinavian Journal of Management 35(3), 101047.

Altersohn, C., (1992). De la Sous-traitance au partenariat industriel, Editions l'Harmattan, Paris.

American Sociology Review, 49(2), pp. 149-164.

Arena R. and Lazaric n., (2003). Nelson and Winter's Evolutionary Theory of Economic Change. Une analyse économique réprospective, Revue économique, vol. 54, No. 2, March 2003, pp. 329-354.

Armenakis A.A. et al., (1993), Creating change readiness for organizational change,

Ayerbe C. and Fonrouge C., (2004). La pérennité de l'activité innovante : une lecture cognitive, Proceedings of the 13th International Conference of the International Association of Strategic Management (AIMS), Le Havre, 1-3 June.

Baudry, B., (1995). L'économie des relations interentreprises, Editions La Découverte, Paris.

Brousseau, E., (1993), La théorie des contrats : technologies de l'information et

Brown S.L. et Eisenhardt K.M, (1997), The Art of Continuous Change: Linking Complexity Theory and Timepace Evolution in Relentlessly Organizations, Administrative Science Quarterly, Vol. 42, pp. 1-34.

Chang, H.K.,. et Gotcher, D.F., (2007). Safeguarding investments and creation of transaction value in asymmetric international subcontracting relationship: the role of relationship learnin and relational capital, Journal of Word Business, 24(4), pp. 477- 488.

Coeurderoy, R., and Quelin, B., (1998), La théorie des coûts de transaction : fondements théoriques et applications managériales, Repenser la stratégie : Fondements et Perspectives, H. Larocheet J.-P. Nioche(eds.), Vuibert, Paris.

Cohen W.M. et Levinthal D.A., 1990, Absorptive capacity: a new perspective on learning and innovation, Administrative Science Quarterly, vol. 35, pp. 128-152.

Collinson, S., \& Liu, Y. (2019). Recombination for innovation: Performance outcomes from international partnerships in China: Recombination for innovation. R\&D Management, 49(1), 46-63.

coordination interentreprises, Paris: Presses universitaires de France.

Cyert R.M. et March J.G., (1963), A behavioral theory of the firm, New Jersey, Prentice Hall.

De la Villarmois O., (2001), Le concept de performance et sa mesure : un état de l'art, in Les Cahiers de la Recherche du Centre Lillois d'Analyse et de Recherche sur l'Evolution des Entreprises, April 2001.

Donada, C., and Kesseler, A., (1997). Partnership: Myths and realities for suppliers: an empirical study in the automotive industry, Proceedings of the International Conference on Co-operation, Luxembourg-Nancy, pp. $1-18$.

Doz Y., (1994), Les dilemmes de la gestion du renouvellement des compétences clés, Revue Française de Gestion, (97), January-February: 92-104.

Dwyer, F.R., Schurr, P.H., et Sejo, O., (1987). Developing Buyer-Seller Relationships, Journal of Marketing, Vol. 51, No. 2 (Apr., 1987), pp. 11-27

Granovetter, M., (1973). The strength of weak ties, American Journal of Sociology, Vol.78, 1360-1380. 
Hamel, G. et Prahalad, C.K., (1990). The Core Competencies of the Corporation, Harvard Business Review, vol. $68, \mathrm{n}^{\circ} 3$.

Hannan M. T. et Freeman J., (1977). The population ecology of organizations, American Journal of Sociology, 82:9, pp. 29-64.

Hannan M. T. et Freeman J., (1984). Structural Inertia and Organizational Change, Human Relations, Vol.46, pp. 681-703.

Järvi, H., Kähkönen, A.-K., \& Torvinen, H. (2018). When value co-creation fails : Reasons that lead to value codestruction. Scandinavian Journal of Management, 34(1), 63-77.

Kamaruddeen A. M. et al., (2009). A proposed framework of measuring firm innovativeness in the housing industrie, The International Journal Of Organizational Innovation, Vol. $2 \mathrm{n}^{\circ} 2$, pp. 101-132.

Liu, J., Yang, P., Xia, B., \& Skitmore, M. (2017). Effect of Perceived Justice on Subcontractor Willingness to Cooperate: The Mediating Role of Relationship Value. Journal of Construction Engineering and Management, 143(9), 04017062.

Martínez-costa, M., Jiménez-Jiménez, D., \& Dine Rabeh, H. A. (2019). The effect of organisational learning on interorganisational collaborations in innovation: An empirical study in SMEs. Knowledge Management Research \& Practice, 17(2), 137-150.

Nelson et Winter, (1982), An Evolutionary Theory of Economic Change, Cambridge (Mass.), Belknap Press/Harvard University Press.

Nwokocha, V. C., Nwankwo, C., \& Madu, I. A. (2019). The role of subcontracting on innovation : An assessment of small and medium enterprises in Nigeria. Production \& Manufacturing Research, 7(1), 88-108.

Palumbo, R., \& Manna, R. (2018). Innovation at the crossroads: An investigation of the link between interorganizational relationships and innovation. International Journal of Organizational Analysis, 26(3), 432-449.

Perret V., (1996), La gestion du changement organisationnel : Articulation de représentations ambivalentes, 5th International Conference on Strategic Management, Lille, 13-15 May 1996.

Quach Th.K.O., (2006), Une perspective de recherche sur la performance dans l'organisation, Paper presented at the 2nd Annual Conference of the Canadian Council for Small Business and Entrepreneurship, Trois-Rivières, 2006.

Quelin, B., (2003), Externalisation stratégique et partenariat: de la firme patrimoniale à la firme contractuelle, Revue Française de Gestion, No. 143, pp. 13-26.

Rejeb, N., and Ghorbel, A., (2004), L'impact de la nouvelle relation de sous-traitance sur la performance des soustraitants : application au cas des Industries Mécaniques et Electriques en Tunisie, 13th AIMS conference, Normandie, Vallée de Seine 2,3 et 4 Juin 2004

Romanelli e. et Tushman M.L., (1994), Organizational Transformation as Punctuated Equilibrium: An Empirical Test, The Academy of Management Journal, 37/5, pp. 1141-1166.

Schlink G., (2006), Determinants of creative idea sharing as an innovation issue. Une application à la relation entre la nouvelle entreprise innovante et son financeur, $\mathrm{PhD}$ thesis in Economic Sciences, Faculty of Economic Sciences and Management of Strasbourg, University Louis Pasteur.

Selnes, F., and Sallis, J., (2003), "Promoting relationship learning", Journal of Marketing, pp. 80-95.

Shurweryimana F., (2015), "Comportements d'innovation organisationnelle et performance des PME exportatrices - Cas des secteurs agroalimentaires et textile au Maroc », Thèse de doctorat en sciences de gestion, GREFSO, Université Cadi Ayyad, Marrakech.

Soparnot R., (2009), Vers une gestion stratégique du changement : une perspective par la capacité organisationnelle de changement, Revue Management \& Avenir, (8), pp. 104-122.

Soulas C., (2006), Capacité d'innovation et routines dans l'approche évolutionniste : des déterminants cognitifs et institutionnels, Cahiers du Centre de Recherche sur l'Entreprise (CEREN) 15(2006), pp. 27-36, ESC DijonBourgogne.

Stoelhorst J.W. et Bridoux Fl., (2006), Beyond Competitive Advantage: What Can Theories of Strategy Explain?, Working paper, Amsterdam Business School, University of Amsterdam.

Williamson, O.E, (1985), The economic institutions of capitalism: firms, market, relational contracting, Free Press, New York.

Williamson, O.E., (1975), Market and hierarchies: analysis and antitrust implications, Free Press, New York.

Zahir M., (2015), Transfert de connaissances et pratiques managériales dans les relations de sous-traitance Grandes entreprises-PME: cas de 1' industrie automobile au Maroc" Thèse de doctorate en sciences de Gestion, Université Cadi Ayyad, Université d'Auvergne

Zahra S. A. et George G., (2002). Absorptive Capacity: A Review, Reconceptualization, and Extension, The Academy of Management Review, 27(2), pp. 185-203. 